\title{
EL DERECHO ADMINISTRATIVO SANCIONADOR PERUANO
}

\section{The administrative law of peruvian sanctioner}

\author{
Víctor Lizárraga Guerra* \\ Universidad Continental
}

\section{Resumen}

El autor da cuenta del panorama general respecto a la regulación del derecho administrativo sancionador en el Perú y concluye con la propuesta de regulación específica de esta manifestación del ius imperium del Estado para la determinación de responsabilidades sobre aquellos que cometieron infracciones

Palabras clave: Potestad sancionadora; garantismo; interés público; interés general; interés colectivo; jurisprudencia.

\section{Abstract}

The author gives an overview of the regulation of administrative sanctioning law in Peru, concluding with the proposal of specific regulation of this statement of the ius imperium of the State for the determination of responsibilities about those who committed offences.

Keywords: Sanctioning power; guarantee; public interest; general interest, collective interest; jurisprudence.

\footnotetext{
* Presidente del Instituto Peruano de Derecho Disciplinario. Profesor en la Escuela Nacional de
} Control y en la Universidad Continental. 
Al iniciar con el desarrollo del presente artículo, he creído conveniente realizar una reflexión sobre la situación en la que se encuentra el derecho administrativo sancionador peruano, sus principales rasgos y las etapas de evolución que ha experimentado a la fecha. Considero que nuestra disciplina se encuentra en etapa de consolidación, debido a las deficiencias normativas y las contradicciones de la jurisprudencia. Es por ello que estamos frente a un adolescente con tutela, en busca de su madurez y posterior consolidación.

Es importante empezar identificando los modelos con los cuales se ha desarrollado el derecho administrativo sancionador. El primero, es derivación del Derecho de Policía, institución por la cual el rey concentraba el poder sancionador, con la finalidad de mantener el orden, seguridad y bienestar de sus vasallos, ordenando (si fuera el caso) a sus funcionarios y jueces la imposición de la sanción administrativa; este modelo cambia luego de la Revolución Francesa de 1789, donde se define la diferenciación desde el punto de vista orgánico entre jueces y funcionarios, y adquiere como características fundacionales la supremacía de la ley y la protección de los derechos individuales, presentándose la división entre delitos e infracciones; cuya solución estuvo a cargo de jueces, por un lado, y de gobernadores, alcaldes o funcionarios, por el otro, recaía el control de las decisiones de estos últimos por los tribunales contenciosos administrativos. Posteriormente, con la consolidación del Estado de Derecho y el reconocimiento constitucional, se instaura un modelo basado en la protección de los derechos individuales, por un lado y, por el otro, en la búsqueda de la consolidación de la administración pública.

En ese contexto, el derecho administrativo tuvo un desarrollo significativo en Francia y luego en Alemania, vertientes que influenciaron significativamente en la España del siglo XIX; el derecho administrativo sancionador español no presentó un avance, sobre todo por su heterogeneidad normativa. Sin embargo, es recién en el siglo XX que la legislación española desarrolla un esquema sancionador para las administraciones públicas a través de las ya derogadas Ley de Régimen Jurídico de la Administración del Estado de 1957 y Ley de Procedimientos Administrativos de 1958, las cuales fueron sustituidas por la Ley de Régimen Jurídico de las Administraciones Públicas y del Procedimiento Administrativo Común [30/1992 -derogada], 
modificada por la Ley 4/1999 de 13 de enero de $1999^{1}$, legislación que influenció en la redacción del capítulo sobre procedimiento sancionador en la Ley N. ${ }^{\circ} 27444$ del año 2001, es por ello que podemos afirmar que nuestro derecho administrativo sancionador tiene una influencia importante del derecho administrativo español y su doctrina contemporánea (Brewer-Carías, $2011)^{2}$.

Esta situación confirma una vez más que, debido a la obsesión por la influencia foránea, los autores intelectuales de la Ley N. ${ }^{\circ} 27444$, dejaron pasar la oportunidad de crear un derecho administrativo sancionador acorde a la realidad peruana, ajustado a proteger el interés colectivo por un lado y por otro, a promover una eficaz y eficiente resolución de las causas administrativas bajo una mirada del pensamiento institucional.

\section{II}

Este vacío (creación de un derecho administrativo propio) que ordinariamente debe ser discutido por el legislador o en su defecto por un ejecutivo en representación de la administración pública ha sido completado fundamentalmente por la jurisprudencia del Tribunal Constitucional y los tribunales jurisdiccionales. A este fenómeno Alejandro Nieto (2012) lo denomina «creación pretoriana». Es decir, el derecho administrativo sancionador peruano, ha tenido una evolución bajo la influencia de actores con pensamiento de protección del orden constitucional y de bienes jurídicos penales.

No cabe duda, que la jurisprudencia constitucional y judicial, son aportes im-

1 Cabe mencionar que recientemente se modificó la Ley 30/1992, a través de la Ley 39/2015, de 1 de octubre, del Procedimiento Administrativo Común de las Administraciones Públicas. Sobre el particular, Tomas Cano Campos (2015) ha denunciado respecto a las últimas reformas españolas lo siguiente:

La potestad sancionadora de la Administración no debe estar regulada en dos textos normativos distintos y, menos aún, de forma fragmentaria y parcial. Esta potestad, al igual que el sistema de responsabilidad de las Administraciones Públicas, debería haberse regulado en un solo texto o disposición normativa y, como se ha adelantado, de forma completa y sistemática y no, como se hace, con carácter fragmentario o parcial, con la merma para la seguridad jurídica que ello supone. Incluso estaría justificada su regulación en una sola Ley, como ocurre en otros países (Alemania e Italia), quizá junto a otra importante y olvidada institución como la inspección administrativa. Es claro que al amparo del art. 149.1.18 $\mathrm{CE}$, el Estado está habilitado para aprobar una ley general y básica sobre la potestad inspectora y sancionadora de la Administración.

2 El autor identifica la misma influencia de la normativa y doctrina española en nuestra Ley del Procedimiento Administrativo General. 
portantes para el derecho, puesto que a través de los casos prácticos se acercan a una realidad. Sin embargo, en el caso peruano se ha identificado que dichas decisiones sobre determinados casos concretos se han visto alejadas de la realidad administrativa e impulsada por un exacerbado garantismo. Con ello no quiero desmerecer los importantes aportes de la jurisprudencia constitucional que, sin duda, han servido para la incorporación de principios como el de culpabilidad en el ordenamiento jurídico administrativo, entre otros.

Frente a esta realidad, por la cual los obligados a desarrollar el derecho administrativo sancionador, que son naturalmente las administraciones públicas, que por reserva de ley tienen reconocido el poder sancionador, se conoce muy poco de sus aportes y contribuciones, salvo honrosas excepciones, pese a que son la voz de los intereses públicos y generales sometidas a la ley, siendo así, sus aportes han sido insuficientes y su voz casi siempre opacada, por lo que se ha presentado un conflicto; por un lado la vertiente garantista, que busca la protección de los derechos de los infractores, que ha sido muy influyente en el derecho administrativo sancionador peruano, tal como se puede apreciar con la últimas reformas a la Ley N. ${ }^{\circ} 27444$ y, por otro lado, la vertiente tradicional, que tiene un enfoque hacia los intereses públicos, generales y colectivos, que representa la administración, que precisamente tiene poca o nula participación, quizá por el poco interés, oportunidad o influencia en la configuración de las normas administrativas.

\section{III}

Ahora bien, toca defender el rol de las administraciones públicas, que con mucha prolijidad llevan adelante su facultad sancionadora: realizan una investigación preliminar, buscan elementos que le otorguen convicción para el inicio del procedimiento sancionador, previa identificación de una supuesta infracción, bajo una adecuada formulación de cargo y desarrollo eficiente del procedimiento, hasta la elaboración del informe de pronunciamiento por parte de la autoridad instructora y una razonable y proporcional sanción emitida por la autoridad sancionadora. Todas estas, actuaciones que pueden ser revistas jurisdiccionalmente por un juez especializado en lo contencioso administrativo, quien en pocas líneas puede confirmar o en su defecto declarar la nulidad de la actuación de la administración, dejando de analizar el interés general que motivó la sanción.

Con ello no estamos cuestionado la labor jurisdiccional, lo que queremos 
es hacer ver que la construcción de un derecho administrativo sancionador debe ser único e integral y si es posible bajo canales de coordinación, con un sistema conceptual y normativo que integre, homogenice y coordine el funcionamiento de todos los regímenes especiales.

En nuestro país, el derecho administrativo ha dejado de ser un instrumento orientado al funcionamiento eficaz y legalmente correcto de la Administración Pública, esto debido a que su construcción y desarrollo está en manos de respetables profesores de derecho administrativo, donde algunos tienen sus intereses particulares en la defensa de sus clientes, transformándolo en un instrumento al servicio de sus estudios jurídicos. Se puede apreciar, por ejemplo, que la mayor parte de los manuales de derecho administrativo, publicados en el Perú, se enfocan mayormente en los modos de paralizar y anular las decisiones de la administración, antes de privilegiar mejoras en las prestaciones y potenciales actividades de la administración. Ello explica la prevalencia del garantismo exacerbado del derecho administrativo sancionador en el Perú, materializada en las últimas reformas a la Ley de Procedimiento Administrativo General.

Algunos pueden calificar mi posición como autoritaria o fanática de lo público, pero puedo decir, en honor de la verdad, que no me sitúo en ninguna de esas posiciones. Creo que, frente a las presiones del interés económico insertadas en las reformas administrativas impuestas por el neoliberalismo, es insoslayable promover la defensa del interés general y así promover un equilibrio que permita concretizar los intereses individuales del infractor con el interés colectivo vulnerado por la infracción, un gran reto para los operadores administrativos.

\section{IV}

Otro aspecto que amerita tratar es el conflicto que se presenta entre el derecho administrativo sancionador y el derecho penal, en un escenario perdurable en el que este último siempre consideró al primero (derecho administrativo sancionador) como un hijastro o un derecho penal de bagatela, a tal extremo que en el artículo III del Código Procesal Penal, se establece la prevalencia del derecho penal sobre el procedimiento administrativo sancionador. Queda claro que el derecho administrativo sancionador es una rama de derecho administrativo y este a su vez pertenece al derecho público, por lo que la relación con el derecho penal solo debe ser 
de carácter técnico, y en la que ambos comparten el respeto a la Constitución y la protección de bienes jurídicos, máxime de la reconocida diferencia entre el derecho penal — represor por antonomasia — y el sancionador que goza de una finalidad preventiva.

Asimismo, es oportuno referirse a la desbordante actividad administrativa en nuestro ordenamiento jurídico peruano, por un lado podemos identificar la potestad sancionadora en materia fiscal, contrataciones públicas, protección del consumidor, medioambiental, funcional, urbanístico, sanitario, entre otros, por lo que cabe preguntarse hasta qué punto puede hablarse de un solo Derecho Administrativo Sancionador ${ }^{3}$. Al respecto, es importante resaltar, con sus deficiencias y limitaciones, la construcción de un esquema unificado en las últimas reformas a la Ley N. ${ }^{\circ} 27444$, en el cual están claramente regulados los principios materiales y formales, las características del procedimiento sancionador y su aplicación obligatoria para las administraciones públicas que cuentan con poder sancionador; sin embargo, este carácter imperativo viene siendo soslayado por algunas entidades públicas, que recurren ante instancias competentes para la exclusión de sus alcances, para privilegiar su normativa especial y argüir su autonomía como fundamento institucional.

Decíamos que el derecho administrativo sancionador peruano es un adolescente camino a la madurez que bajo el control de un tutor sobreprotector (representado por destacados profesores de derecho administrativo con intereses en la defensa técnica), se convierte en un adolescente temeroso e inseguro (elección entre el garantismo o la eficacia), respecto a la definición de su personalidad, puesto que recibe consejos de diferentes actores (influencia de las sentencias del TC y las decisiones jurisdiccionales, entre otros), respecto a su modelo de vida, que le impide sentar las bases de su personalidad para la toma independiente de sus decisiones (construcción teórica y dogmática

3 Tomas Cano Campos (2015), refiriéndose al modelo español señala: que «[a]l punto que, incluso, cabe plantearse si puede hablarse hoy de un solo Derecho administrativo sancionador y no de tantos Derechos sancionadores como sectores ordinamentales con características singulares hay (fiscal, social, tráfico, policía, medioambiente, urbanismo, sanitario, etc.), de modo que es preciso un sistema conceptual y normativo que integre, homogenice y coordine el funcionamiento de todos estos regímenes positivos que se entrecruzan territorial y materialmente.» 
del derecho administrativo sancionador, alejada de la influencia penalista). Aspiro en un futuro que esta etapa de madurez implique la aprobación de una ley general sobre la facultad sancionadora reconocida a la Administración que, además de los principios reconocidos, ofrezca un cuadro legislativo homogéneo y general de las infracciones y sanciones, y regule los elementos y características esenciales del procedimiento administrativo sancionador. En definitiva, lo que se busca sería una parte general del Derecho Administrativo Sancionador, que regule con flexibilidad tales cuestione y permita que la legislación especial pueda incluir las especialidades y rasgos necesarios en aquellos aspectos no necesitados de una regulación uniforme y se deje de invenciones contradictorias, como las previstas en el artículo II del Texto Único Ordenado de la Ley N. ${ }^{\circ}$ 27444, donde se fija una regla inédita en la interpretación jurídica peruana y se obliga a las administraciones con procedimientos especiales someter su regulación a las normas comunes, prevista por una reforma polémica para los intereses colectivos.

\section{BIBLIOGRAFÍA}

Brewer-Carías, A. (2011). La regulación del procedimiento administrativo en América Latina con ocasión de la primera década (2001-2011) de la Ley de Procedimiento Administrativo General del Perú (Ley 27444). Derecho PUCP. 67, pp. 47-76.

Cano T. (2015). La potestad sancionadora de la administración: una regulación fragmentaria, incompleta y perniciosa. Documentación administrativa: Nueva Época. Enero-diciembre.

Nieto, Alejandro (2012). Derecho administrativo sancionador. 5a. ed. Madrid: Tecnos. 